\title{
Preoperative versus intraoperative localization of pulmonary nodules
}

\author{
Andrew Tang, MD, and Usman Ahmad, MD
}

\footnotetext{
From the Department of Cardiothoracic Surgery, Heart and Vascular Institute, Cleveland Clinic, Cleveland, Ohio. Disclosures: Authors have nothing to disclose with regard to commercial support.

Received for publication July 27, 2018; accepted for publication July 30, 2018; available ahead of print Aug 29, 2018

Address for reprints: Usman Ahmad, MD, Department of Cardiothoracic Surgery, Heart and Vascular Institute, Cleveland Clinic, 9500 Euclid Ave, J4-1, Cleveland, OH (E-mail: ahmadu@ccf.org).

J Thorac Cardiovasc Surg 2018;156:1970-1

$0022-5223 / \$ 36.00$

Copyright (C) 2018 Published by Elsevier Inc. on behalf of The American Association for Thoracic Surgery https://doi.org/10.1016/j.jtcvs.2018.07.090
}

Successful localization of deep subcentimeter tumors has made resection without digital palpation possible..$^{1-5}$ This is a useful adjunct to minimally invasive pulmonary resection. Several techniques of localization are being utilized and at this time, the choice depends upon the treating physician and available resources. ${ }^{1-5}$

Chao and colleagues ${ }^{6}$ meticulously tracked patients undergoing computed tomography (CT) guided videoassisted thoracoscopic resection of small indeterminate pulmonary nodules. They compared the efficacy and safety of preoperative CT (POCT) versus intraoperative CT (IOCT) guided localization. Patients with subcentimeter or deep (ie, $>1 \mathrm{~cm}$ from visceral pleura) single solid nodules underwent CT-guided localization using either POCT or IOCT depending on hybrid operating room availability. Preoperative localization was performed by interventional radiologists with CT guidance. Intraoperative procedures were performed in the operating room by members of the thoracic surgery team under fluoroscopic guidance and confirmed with CT.

The group's experience highlights several points. The first important observation is that $100 \%$ success in targeting can be achieved regardless of who performs the localization procedure, whether it is an interventional radiologist or a thoracic surgeon. There was no difference in localization procedure time or radiation exposure to the patient between POCT and IOCT. The localization-to-surgery interval was longer in the POCT group, as expected. It is not surprising that more patients in this group developed subclinical pneumothoraces and pulmonary hemorrhage, none of which were clinically significant. The wide range of time between localization and surgery can theoretically amplify the consequences of these complications in POCT group patients. Surgery occurred anywhere between 3 and 4 hours after localization in the POCT group. With $46.7 \%$ of the POCT group developing pneumothorax and $13.3 \%$ developing parenchymal bleeding, there is a 3 - to 4-hour window during which a patient could possibly decompensate on the wards.

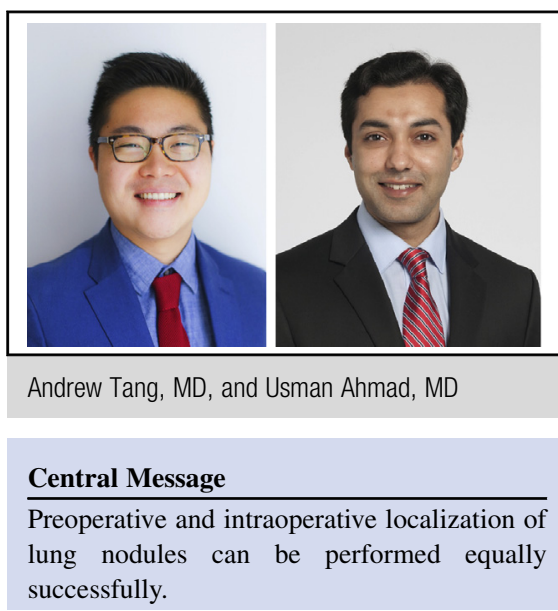

See Article page 1974.
There was no difference in the success of intraoperative localization between the 2 groups. Intraoperative localization carries a theoretically lower risk of wire dislodgement or diffusion of dye compared with $\mathrm{POCT}^{4,5}$; however, the overall success rate of intraoperative localization was $92.2 \%$ with no difference between the 2 groups. This could be confounded by differences in the localization techniques between the 2 groups because the POCT group had more dye injections and IOCT group had more wire localizations. To determine the true difference of intraoperative localization efficacy, it would be important to randomize and achieve balanced groups based on localization techniques in addition to the variables that the authors have already listed.

The choice of procedure in this case was based on availability of the operating room. Although this may have an influence on introducing bias, it does reflect the real-life challenge. ${ }^{4,5}$ Ultimately, the goal is to provide safe, effective care in a timely fashion. Whichever technique allows that to happen would be the preferred approach at a given institution. Time in the operating room is typically the most expensive commodity in most hospitals. It would be useful to take that into account in this analysis. These points would not have been elucidated if not for the authors' detailed breakdown and tracking of the process. The authors should be congratulated for their meticulous bookkeeping because it provides a nice template for future randomized studies comparing IOCT with POCT. 


\section{References}

1. Finley RJ, Mayo JR, Grant K, Clifton JC, English J, Leo J, et al. Preoperative computed tomography-guided microcoil localization of small peripheral pulmonary nodules: a prospective randomized controlled trial. J Thorac Cardiovasc Surg. 2015;149:26-32.

2. Sancheti MS, Lee R, Ahmed SU, Pickens A, Fernandez FG, Small WC, et al. Percutaneous fiducial localization for thoracoscopic wedge resection of small pulmonary nodules. Ann Thorac Surg. 2014;97:1914-9.

3. Hanauer M, Perentes JY, Krueger T, Ris HB, Bize P, Schmidt S, et al. Preoperative localization of solitary pulmonary nodules with computed

tomography-guided hook wire: report of 181 patients. J Thorac Cardiovasc Surg. 2016;11:5

4. Yang SM, Ko WC, Lin MW, Hsu HH, Chan CY, Wu IH, et al. Image-guided thoracoscopic surgery with dye localization in a hybrid operating room. J Thorac Dis. 2016;8(Suppl 9):S681-9.

5. Zhao ZR, Lau RW, Yu PS, Wong RH, Ng CS. Image-guided localization of small lung nodules in video-assisted thoracic surgery. J Thorac Dis. 2016;8(Suppl 9):S731-7.

6. Chao YK, Pan KT, Wen CT, Fang HY, Hsieh MJ. A comparison of efficacy and safety of preoperative versus intraoperative computed tomography-guided thoracoscopic lung resection. J Thorac Cardiovasc Surg. 2018;156:1974-83. 